\title{
O Papel do enfermeiro frente ao câncer de colo uterino
}

\author{
The role of nurses in the face of cervical câncer \\ El papel de las enfermeras frente al cáncer cervical
}

Cláudia Priscila Fonseca Carneiro ${ }^{1 *}$, Danilo Moreira Pereira ${ }^{1}$, Amanda Torres Pereira ${ }^{1}$, Gislaine Aparecida Silva Santos ${ }^{1}$, Fernanda Aparecida da Silva de Moraes ${ }^{1}$, Rosilei de Fátima Rodrigues Duarte ${ }^{1}$.

\begin{abstract}
RESUMO
Objetivo: Descrever quais são as atribuições do enfermeiro no manejo do câncer de colo uterino (CCU), desde sua prevenção até o momento da doença já instalada. Métodos: Trata-se de um estudo de uma Revisão de Literatura, qualitativa e descritiva que utilizou as plataformas Literatura Latino-americana e do Caribe em Ciências da Saúde (LILACS), Scientific Eletronic Library Online (Scielo), Google Acadêmico e cartilhas do Ministério da Saúde. Para critério de escolha utilizou-se artigos científicos publicados entre os anos de 2008 a 2018, na língua portuguesa e na íntegra. Onde foram selecionados 23 artigos que atenderam aos métodos de inclusão estabelecidos onde permitiu abordagem sobre o papel de enfermeiro em reconhecer os fatores que influenciam no (CCU), na prevenção primária e secundária e no tratamento da doença. Resultados: O câncer de colo uterino tem seu desenvolvimento quando as células que revestem o epitélio começam sofrer alterações e se multiplicam desordenadamente, podendo comprometer tecidos, estruturas e órgãos próximos ou à distância. No Brasil nos anos biênios 2018/2019 são pressupostos 16.370 casos um risco de 15,43 a cada 100 mil mulheres brasileiras. Conclusão: Conclui-se que o enfermeiro possui uma atribuição de suma relevância em todo processo do câncer de colo de útero desde sua prevenção, rastreamento precoce até seu tratamento.
\end{abstract}

Palavras-chave Câncer do colo do útero, Enfermagem, Prevenção, Tratamento.

\begin{abstract}
Objective: Describe the nurses' attributions to cervical câncer (CC), from its prevention to the moment of the already installed disease. Methods: This is a study of a qualitative and descriptive Literature Review that used the platforms Latin American and Caribbean Health Sciences Literature (LILACS), Scientific Eletronic Library Online (Scielo), Google Scholar and booklets of the Ministry of Health. For selection criteria, scientific articles published between the years 2008 to 2018, in Portuguese language. In which 23 articles were selected that met the established inclusion methods, which allowed us to approach the role of nurses in recognizing the factors that influence (CC), primary and secondary prevention and treatment of the disease. Results: Cervical cancer develops when the cells lining the epithelium begin to change and multiply in a disorder that may compromise near or distant tissues, structures and organs. In Brazil, in the 2018/2019 biennium years, an estimated 16,370 cases, a risk of 15.43 per 100,000 Brazilian women. Conclusion: It is concluded that the nurse has a very relevant attribution in the whole process of cervical cancer since its prevention, early screening until its treatment.
\end{abstract}

Keywords Cervical cancer, Nursing, Prevention, Treatment.

1 Faculdade Anhanguera de São José dos Campos-SP, Brasil. *E-mail: prikacfc@gmail.com

SUBMETIDO EM: 8/2019

ACEITO EM: 9/2019

PUBLICADO EM: 10/2019

REAS/EJCH | Vol.Sup.35 | e1362 | DOI: https://doi.org/10.25248/reas.e1362.2019 Página 1 de $\mathbf{9}$ 


\section{RESUMEN}

Meta: Describa cuáles son los deberes de la enfermera en el tratamiento del cáncer de cuello uterino (CCU), desde su prevención hasta el momento de la enfermedad ya instalada. Métodos: Este es un estudio de una Revisión de literatura cualitativa y descriptiva que utilizó las plataformas Literatura Latinoamericana y del Caribe en Ciencias de la Salud (LILACS), Scientific Eletronic Library Online (Scielo), Google Scholar y los folletos del Ministerio de Salud. Para los criterios de selección, artículos científicos publicados entre los años 2008 y 2018, en portugués y en su totalidad. En el cual se seleccionaron 23 artículos que cumplían con los métodos de inclusión establecidos, lo que nos permitió abordar el papel de las enfermeras en el reconocimiento de los factores que influyen en la (CCU), la prevención primaria y secundaria y el tratamiento de la enfermedad. Resultados: El cáncer cervical se desarrolla cuando las células que recubren el epitelio comienzan a cambiar y se multiplican en un trastorno que puede comprometer tejidos, estructuras y órganos cercanos o distantes. En Brasil, en el bienio 2018/2019, se estima que hay 16,370 casos, un riesgo de 15.43 por 100,000 mujeres brasileñas. Conclusión: Se concluye que la enfermera tiene una atribución muy relevante en todo el proceso de cáncer cervical desde su prevención, detección temprana hasta su tratamiento.

Palabras clave Cáncer cervical, Enfermería, Prevención, Tratamiento.

\section{INTRODUÇÃO}

O câncer de colo uterino (CCU) tem seu desenvolvimento quando as células que revestem o epitélio começam sofrer alterações e se multiplicam desordenadamente, podendo comprometer tecidos, estruturas e órgãos próximos ou à distância (OLIVEIRA JRG, 2014). São divididos em duas classes, o que se inicia no epitélio escamoso é designado carcinoma epidermóide, é o mais incidente, e o que tem sua iniciação no epitélio glandular designa-se adenocarcinoma, este mais atípico e mais agressivo (AMARAL MS et al., 2017).

Segundo Almeida AF et al. (2015), o CCU é uma doença progressiva e lenta, antes de se tornar maligna ocorrem várias alterações no epitélio que estão ligadas a fatores que a mulher foi exposta durante sua vida. Do processo de iniciação da lesão para a forma mais agressiva e invasiva pode levar até 20 anos para seu desenvolvimento (OLIVEIRA JRG, 2014). Essas alterações se desenvolvem em estágios de neoplasias intraepitelial (NIC), quando maior for o grau do NIC maior os riscos das lesões se tornarem malignas. Essas lesões denominadas precursoras são curáveis com a probabilidade de quase $100 \%$ de cura se diagnosticada em sua fase inicial (AMARAL AF et al., 2017).

De acordo com o Instituto Nacional do Câncer (INCA) (2017), o Papilomavírus humano (HPV) é o principal fator de risco para desenvolvimento do CCU estando presente em quase $100 \%$ dos casos. Pressupõe-se que $40 \%$ das mulheres sexualmente ativas estão infectadas pelo HPV, as cepas oncogênicas 16 e 18 são as de alto risco para desenvolvimento do câncer epitelial escamoso de alto grau, presente em quase $70 \%$ nos casos. Porém há outros fatores que contribuem para desenvolvimento de CCU, sendo eles: vida sexual precoce, múltiplos parceiros, Infecção Sexualmente Transmissíveis (IST), multiparidade, tabagismo, contraceptivo oral prolongado, má nutrição, má higiene além de fatores genéticos e imunológicos (MATTOS CDT et al., 2014).

No Brasil o CCU ocupa a terceira posição entre as neoplasias malignas que afetam mulheres, ficando atrás somente do câncer de mama e câncer colorretal, a estimativa de novos casos para os anos consecutivos de 2018-2019 são de 16.370 mil (INCA, 2018). Já a mortalidade segundo o INCA (2017), aumenta progressivamente após os 40 anos de idade com grande diferença entre as regiões brasileiras.

Em maio de 2014 foi lançado pelo Ministério da Saúde (MS) a Política de Atenção a Saúde da Mulher que teve como uns dos objetivos fortalecer a prevenção de câncer de colo de útero com ações educativas em saúde e ressaltando a importância de realizar exames de rastreamento. Com isso a diligência do enfermeiro na prevenção do câncer de colo uterino é essencial através da prevenção primária e secundária realizando ações que objetivam o controle de câncer cervical atuando na promoção, prevenção, rastreamento, detecção precoce, diagnósticos, tratamento, reabilitações e cuidados paliativos (BATISTA RCL, 2015). 
Trata-se de uma revisão de literatura com o objetivo de descrever quais são as atribuições do enfermeiro na prevenção e manejo do câncer de colo uterino.

\section{MÉTODOS}

Foi realizada uma Revisão integrativa de literatura sobre o papel do Enfermeiro frente o câncer do colo uterino em todo o processo desde a prevenção até a instalação da doença. A revisão integrativa baseia-se nas seguintes etapas: escolha do tema e dos objetivos da revisão, leitura dos títulos e resumos, separação dos artigos, definição dos critérios de inclusão e exclusão, leitura dos artigos na integra, interpretação e apresentação das informações.

O levantamento bibliográfico foi realizado nas bases de Literatura Latino-americana e do Caribe em Ciências da Saúde (LILACS), Scientific Eletronic Library Online (Scielo), Google Acadêmico e cartilhas do Ministério da Saúde. Para critério de inclusão utilizou-se artigos científicos publicados entre os anos de 2008 a 2018. Como critérios de inclusão foram selecionados 23 artigos que melhor abordaram a temática sobre a função do enfermeiro em reconhecer os fatores que influenciam no CCU, prevenção primária e secundária e tratamento da doença, além de estarem em português, todavia como critérios de exclusão 17 artigos foram eliminados por não abordarem adequadamente a temática escolhida.

Os descritores de saúde utilizados para essa pesquisa foram: Câncer do colo do útero, enfermagem, prevenção e tratamento.

\section{RESULTADOS e DISCUSSÃO}

O câncer de modo geral é caracterizado por ser uma doença crônica e degenerativa, que tem sua iniciação com alterações nos genes de uma célula, seu desenvolvimento acontece quando todos os mecanismos do sistema imunológico falham (PAULA CG et al., 2012). No câncer de colo uterino as células que revestem o epitélio começam sofrer alterações e se multiplicam desordenadamente, podendo comprometer tecidos, estruturas e órgãos próximos ou à distância (OLIVEIRA JRG, 2014).

Conforme INCA (2017), são estimados 530 mil novos casos por ano em todo mundo, sendo o quarto tipo de câncer mais incidentes em mulheres e quarta causa de mortalidade no mundo, com registro de 265 mil óbitos por ano, a incidência e mortalidade é mais evidente em países em desenvolvimento. Já no Brasil nos anos biênios 2018/2019 são estimados 16.370 casos de CCU, um risco de 15,43 a cada 100 mil mulheres brasileiras (INCA, 2018).

A idade com maior incidência para o câncer de colo do útero é entre 45 a 50 anos, no entanto a faixa de maior detecção de lesões percussoras ocorre entre os 20 e 29 anos de idade (CASARIN MR e PICCOLI JCE, 2011). Já a mortalidade segundo INCA (2017), aumenta progressivamente após os 40 anos de idade com grande diferença entre as regiões brasileiras. O óbito na região Norte se destaca pela maior taxa do país, em 2016 a taxa foi de 11,07/100 mil mulheres, seguidos da região Nordeste e Centro-Oeste, Sul e Sudeste.

De acordo com Barbosa S et al. (2011), nos anos 1979 a 2004 o CCU ocupou $14^{\circ}$ posição entre as 15 causas mais relevantes de morte entre mulheres. Para uma redução da mortalidade são necessários métodos de prevenção ao longo de toda vida, principalmente para HPV um dos principais fatores para desenvolvimento do $\mathrm{CCU}$, uma detecção precoce e tratamento de lesões pré-cancerígenas e tratamento correto e hábil no diagnóstico da patologia (TSUCHIYA CT et al., 2017).

Em uma comparação entre o Brasil e outros países do mundo sobre incidência e mortalidade, o Brasil ficou na média em relação aos países em desenvolvimento, mas em relação aos países desenvolvidos sua taxa foi bem maior (TSUCHIYA CT et al., 2017).

A análise dos artigos selecionados para a revisão que possuíam como objetivos de compreender a função do enfermeiro em reconhecer os fatores que influenciam no $\mathrm{CCU}$, na prevenção primária, secundária e no tratamento da doença permitiram a construção da Tabela 1, que pode ser observada abaixo: 
Tabela 1 - Artigos utilizados na revisão de literatura sobre CCU.

\begin{tabular}{|c|c|c|c|}
\hline Autor & Ano & Revista & Objetivo do trabalho \\
\hline $\begin{array}{l}\text { Almeida AF, et } \\
\text { al. }\end{array}$ & 2015 & Rev. Enferm. UFPE & $\begin{array}{l}\text { Identificar o conhecimento e utilização dos métodos de deteç̧ão do câncer de útero pelas profissionais de } \\
\text { saúde de um hospital. }\end{array}$ \\
\hline Amaral MS, et al. & 2011 & $\begin{array}{l}\text { Revista Cultural e } \\
\text { Científica do UNIFACEX }\end{array}$ & $\begin{array}{l}\text { O objetivo deste estudo foi analisar a importância do enfermeiro na prevenção do câncer de colo e sua } \\
\text { atuação profissional no contexto da estratégia saúde da família. }\end{array}$ \\
\hline Barbosa S, et al. & 2011 & $\begin{array}{l}\text { Revista Cultural e } \\
\text { Científica do UNIFACEX }\end{array}$ & $\begin{array}{l}\text { Delimita-se, como objetivo geral, identificar e descrever as ações desenvolvidas pelo enfermeiro na } \\
\text { prevenção primária e secundária do câncer de colo de útero no âmbito da atenção básica. }\end{array}$ \\
\hline Batista CRL & 2015 & $\begin{array}{l}\text { Universidade de Brasília- } \\
\text { Faculdade de Ceilândia }\end{array}$ & $\begin{array}{l}\text { Objetivo de descrever por meio de revisão de literatura a assistência de enfermagem na prevenção, } \\
\text { diagnóstico e tratamento do câncer de colo uterino. }\end{array}$ \\
\hline Borba OS & 2010 & $\begin{array}{l}\text { Biblioteca } \\
\text { Saúde }\end{array}$ & $\begin{array}{l}\text { Tem como finalidade precípua expor a verdade científica sobre as vacinas que imprudentemente se } \\
\text { denominam de "vacinas contra o câncer do colo do útero". }\end{array}$ \\
\hline $\begin{array}{l}\text { Casarin MR, } \\
\text { Piccoli JCE }\end{array}$ & 2011 & Ciência \& saúde coletiva & $\begin{array}{l}\text { O estudo foi direcionado no sentido de dar relevância à promoção da saúde e à prevenção do câncer, } \\
\text { buscando evitar a doença e obter melhores condições de vida para as mulheres. }\end{array}$ \\
\hline Corrêa LD & 2011 & $\begin{array}{l}\text { Ministério Da Saúde } \\
\text { Instituto Nacional de } \\
\text { câncer José de Alencar } \\
\text { Gomes da Silva }\end{array}$ & $\begin{array}{l}\text { Identificar os diagnósticos de Enfermagem mais prevalentes em pacientes com tumores de colo do útero } \\
\text { no momento da internação na unidade II do Hospital de câncer. } \\
\text { Identificar as características definidoras e os fatores relacionados ao diagnóstico de enfermagem de acordo } \\
\text { com a taxonomia da North American Diagnosis Association (NANDA) de 2009/2011. }\end{array}$ \\
\hline Costa FKM et al. & 2017 & Revista de gestão e saúde & $\begin{array}{l}\text { O objetivo deste estudo é conscientizar uso do exame citopatológico como método de prevenção e relatar } \\
\text { as dificuldades que o enfermeiro enfrenta para realizar coleta e do que ele dispõe para melhorar a adesão } \\
\text { da população feminina. }\end{array}$ \\
\hline Dallabrida FA & 2014 & $\begin{array}{l}\text { Revista da Rede de } \\
\text { Enfermagem do Nordeste }\end{array}$ & O estudo objetivou avaliar a Qualidade de Vida de mulheres com câncer do colo uterino. \\
\hline Duarte SJH & 2011 & Ciencia Y Enfermeria & $\begin{array}{l}\text { O estudo objetivou identificar fatores de risco para câncer de colo uterino entre mulheres com resultados } \\
\text { alterados de exames de Papanicolau, residentes em uma das áreas de abrangência da Estratégia Saúde } \\
\text { da Família no município de Cuiabá, MT, onde o Projeto PETSAÚDE/Saúde da Família está implantado. }\end{array}$ \\
\hline $\begin{array}{l}\text { Farias ACB e } \\
\text { Barbieri AR }\end{array}$ & 2016 & Escola Anna Nery & $\begin{array}{l}\text { Discutir o fluxo assistencial das mulheres com resultado do exame citopatológico alterado em uma rede } \\
\text { de atenção à saúde. }\end{array}$ \\
\hline $\begin{array}{l}\text { Mattos CTD, et } \\
\text { al. }\end{array}$ & 2014 & Revista Pró-UniverSUS & $\begin{array}{l}\text { Com base no descrito delimitamos como objeto de estudo da pesquisa a percepção das mulheres frente } \\
\text { ao diagnóstico e tratamento do câncer do colo do útero. }\end{array}$ \\
\hline
\end{tabular}




\begin{tabular}{|c|c|c|c|}
\hline $\begin{array}{l}\text { Mello SCCS, et } \\
\text { al. }\end{array}$ & 2009 & $\begin{array}{l}\text { Revista Gaúcha de } \\
\text { Enfermagem }\end{array}$ & $\begin{array}{l}\text { O objetivo do estudo foi verificar alterações citopatológicas e fatores de risco para o câncer de colo uterino } \\
\text { em mulheres usuárias do Sistema Único de Saúde de um município de pequeno porte do norte do Paraná, } \\
\text { de } 2001 \text { a } 2006 \text {. }\end{array}$ \\
\hline Mistura C, et al. & 2011 & Revista Contexto e Saúde & $\begin{array}{l}\text { O objetivo central deste estudo foi evidenciar as ações do enfermeiro para o diagnóstico precoce do câncer } \\
\text { de colo de útero, mediante sua inserção na Estratégia Saúde da Família. }\end{array}$ \\
\hline Nascimento PN & 2010 & $\begin{array}{l}\text { Universidade Federal de } \\
\text { Minas Gerais }\end{array}$ & $\begin{array}{l}\text { O objetivo desse estudo é analisar a literatura de enfermagem publicada nos últimos } 10 \text { anos sobre relação } \\
\text { enfermeiro pacientes na consulta preventiva do câncer cérvico uterino. }\end{array}$ \\
\hline Oliveira JRG & 2014 & $\begin{array}{l}\text { Faculdade de Educação e } \\
\text { Meio Ambiente FAEME }\end{array}$ & $\begin{array}{l}\text { Este trabalho objetiva descrever os principais fatores de risco para o desenvolvimento do câncer de colo } \\
\text { do útero. }\end{array}$ \\
\hline Paula CG et al. & 2013 & $\begin{array}{lr}\text { Pós Rev. } & \text { Centro } \\
\text { Universitário } & \text { Newton } \\
\text { Paiva } & \end{array}$ & $\begin{array}{l}\text { Este estudo se baseia em uma revisão de literatura descritiva e prospectiva com abordagem qualitativa, } \\
\text { tendo como objetivo descrever o papel do enfermeiro na prevenção do câncer do colo do útero no âmbito } \\
\text { da atenção básica. }\end{array}$ \\
\hline $\begin{array}{l}\text { Salimena AMO, } \\
\text { et al. }\end{array}$ & 2014 & $\begin{array}{l}\text { Revista de Enfermagem } \\
\text { do Centro Oeste Mineiro }\end{array}$ & $\begin{array}{l}\text { Estudo de natureza qualitativa com objetivo de conhecer a percepção da mulher acometida pelo câncer } \\
\text { de colo uterino sobre a assistência de enfermagem no itinerário do tratamento. }\end{array}$ \\
\hline $\begin{array}{l}\text { Santos LM, Da } \\
\text { Silva Lima, AKB. }\end{array}$ & 2014 & $\begin{array}{l}\text { Revista Baiana de Saúde } \\
\text { Pública }\end{array}$ & $\begin{array}{l}\text { Este estudo objetivou: descrever os fatores de risco ao câncer do colo do útero em mulheres entre } 25 \text { e } 64 \\
\text { anos de idade; determinar a importância da atuação do enfermeiro na prevenção dessa neoplasia; e } \\
\text { destacar a importância de sua detecção precoce. }\end{array}$ \\
\hline $\begin{array}{l}\text { Santos UM, } \\
\text { Souza SEBD }\end{array}$ & 2014 & $\begin{array}{l}\text { Revista Baiana de Saúde } \\
\text { Pública }\end{array}$ & $\begin{array}{l}\text { O objetivo deste artigo é discutir a importância do exame de Papanicolau na prevenção do câncer de colo } \\
\text { do útero e identificar os fatores que dificultam a realização do exame. }\end{array}$ \\
\hline $\begin{array}{l}\text { Tsuchiya CT, et } \\
\text { al. }\end{array}$ & 2017 & Jornal Bras Econ Saúde & Artigo de revisão: uma retrospectiva sobre as políticas públicas voltadas à saúde da mulher \\
\hline $\begin{array}{l}\text { Vargas MAO, et } \\
\text { al. }\end{array}$ & 2013 & $\begin{array}{l}\text { Universidade Federal de } \\
\text { Santa Catarina }\end{array}$ & $\begin{array}{l}\text { Reconhecer o acolhimento, o vínculo e a responsabilização como estratégias para a integralidade do } \\
\text { cuidado e a sistematização da assistência de enfermagem como uma ferramenta para o cuidado à pessoa } \\
\text { com Câncer de Mama, Câncer do Colo do Útero e Tumores da Próstata; refletir sobre as linhas de cuidado } \\
\text { e sua aplicação na atenção à pessoa com Câncer de Mama, Câncer do Colo do Útero e Tumores da } \\
\text { Próstata, com fundamentos nos protocolos clínicos específicos. }\end{array}$ \\
\hline $\begin{array}{l}\text { Veras } \text { JMMF, } \\
\text { Nery IS }\end{array}$ & 2011 & $\begin{array}{l}\text { Revista Interdisciplinar } \\
\text { NOVAFAPI }\end{array}$ & $\begin{array}{l}\text { Este estudo tem como objetivo descrever e analisar as vivências de mulheres com câncer de colo uterino, } \\
\text { frente às alterações biopsicossociais e culturais ocorridas em suas vidas após o diagnóstico. }\end{array}$ \\
\hline
\end{tabular}

Fonte: Carneiro CPF et al., 2019. 
Conforme Casarin MR e Piccoli JCE (2011), e Oliveira JRG (2014), a mortalidade e prevalência do CCU dá se em meio social e nível socioeconômico mais baixo no mundo todo, esses fatores sociais tornam essa população mais vulnerável pela falta de acesso à rede de serviços de saúde para uma intervenção precoce.

Segundo Mistura C et al. (2014), a prevenção para este tipo de câncer pode ser dividida em prevenções primárias e secundárias, as prevenções primárias têm baixo custo, seriam a educação em saúde promovendo o uso de preservativos eliminando a fatores de risco, e fortalecendo intervenções como a vacina da HPV disponíveis na saúde pública para meninos e meninas até 14 anos. A secundária diminui a incidência, prevalência e a mortalidade da doença como o rastreamento pelo exame de citopatologia oncótica para detectar precocemente as lesões precursoras (TSUCHIYA CT et al., 2017).

Para garantir a efetividade dos rastreamentos o Ministério da Saúde vem instituindo programas para fortalecer as politicas de saúde para mulheres, em 1986 foi lançado o Programa de Assistência Integral a Saúde da Mulher (PAISM) que forneceu diretrizes sobre o exame citopatologia oncótico (FARIAS ACB e BARBIERI AR, 2016). Mais tarde em 1997 instituiu o Programa Nacional de Combate ao Câncer do Colo do Útero (PNCC) que continuou a promover o exame cipatológico como o principal método de rastreamento para o CCU (BARBOSA S et al., 2011).

O HPV é um ácido Desoxirribonucleico- vírus (DNA-vírus) faz parte da família Papovavidae composto de 100 tipos de vírus sendo que 50 deles atuam na mucosa genital, sua preferência é por células escamosas causando irregularidades na maturação e diferenciação do epitélio (OLIVEIRA JRG, 2014). Segundo Mattos CTD et al. (2014), estima-se que $40 \%$ das mulheres sexualmente ativas estão infectadas pelo HPV, as cepas oncogênicas são as $16,18,31,33,45,58$ o 6 e o 11 são os responsáveis pelas verrugas vulvares, as 16 e 18 são as de alto risco para desenvolvimento do câncer epitelial escamoso de alto grau, presente em quase $70 \%$ dos casos.

Duarte SJH et al. (2011), apontam que mulheres que apresentaram HPV, relataram relação sexual sem preservativo ao menos uma vez em sua vida, enquanto aquelas que mantiveram vida conjugal estável apresentaram menos índice de HPV.

Porém Mattos CTD et al. (2014), aponta em seu estudo que há outros fatores de risco que contribuem para desenvolvimento de CCU, são eles: vida sexual precoce, múltiplos parceiros, Infecção Sexualmente Transmissíveis (ISTs), multiparidade, tabagismo, contraceptivo oral prolongado, má nutrição, má higiene além de fatores genéticos e imunológicos.

Cabe aos enfermeiros por sua proximidade com a população, uma educação em saúde de maneira integral, incentivando as consultas de enfermagem, abordagens para esclarecimento de dúvidas, riscos, sinais e sintomas, pois essas práticas favorecem mudanças de comportamentos e de atitudes das mulheres (MISTURA C et al., 2011; AMARAL MS et al., 2017).

Ainda sobre educação em saúde é importante que o enfermeiro destaque a relevância da realização do Papanicolau periodicamente e os riscos ao deixar de realizá-lo, sempre explicando como o exame é realizado, assim promovendo vínculo enfermeiro-cliente reduzindo preconceitos e mitos sobre o exame, promovendo um ambiente adequado, passando confiança para que as mulheres possam expressar suas queixas e dúvidas (NASCIMENTO RP, 2010; BATISTA RCL, 2015).

Segundo Costa FKM et al. (2017), o enfermeiro pode direcionar atividades de acordo com o perfil da comunidade, para tal, pode contar com apoio de Agentes Comunitários de Saúde, e para uma atuação ativa de educação em saúde deve-se ensinar profissionais de enfermagem a aconselhar mulheres em salas de espera a marcar consultas com a enfermeira ou médico para realização do Papanicolau.

Outra maneira de prevenção primária apontada por Santos UM e Souza SEB (2013), é a vacina da HPV para prevenir a infecção por esses tipos de HPV. Foi desenvolvida a vacina, com eficácia de $91,6 \%$ nos casos de incidência e de até $100 \%$ em casos persistentes, por isso é destacada com uma das principais fontes de prevenção. A vacina promove redução de custos financeiros e humanos associados ao HPV e câncer de colo uterino (SANTOS UM e SOUZA SEB, 2013; BORBA PC et al., 2010). 
A prevenção secundária segundo Santos LM e Lima AKB (2016) é caracterizada pelo exame de citopatologia oncótica (Papanicolau), um exame de rastreamento que detecta o câncer cervical in situ ou lesões precursoras, que se detectadas precocemente são tratáveis e curáveis em até $100 \%$ dos casos, recomenda-se que toda mulher sexualmente ativa realize o exame de citopalogia oncótico anualmente, após dois resultados consecutivos negativos pode ser realizado a cada três anos (SANTOS UM e SOUZA SEB, 2013).

Existem outros tipos de rastreamento apontados por Oliveira JRG (2014), são eles: colposcopia, cervicografia e teste de DNA do vírus HPV, mas o Papanicolau é considerado por ser mais efetivo, além de indolor e ter baixo custo para sua realização.

O enfermeiro é habilitado ao longo de sua vida acadêmica para coleta de exame de citopatologia oncótica e possui respaldo pela Lei do Exercício Profissional 7.498/86, além da coleta do material para realização do exame tem habilidade de interpretar resultados, fazer encaminhamento quando necessário e monitorar casos de suspeita e confirmados de câncer cervical (BATISTA RCL, 2015; NASCIMENTO RP, 2010).

Barbosa S, et al. (2011) aponta que o enfermeiro além da execução do exame preventivo é responsável por preenchimentos de documentos necessários para exames, bem como anotação no prontuário, uma contínua monitoração dessas pacientes nas próximas consultas, por alimentar sistemas de informações como - SICOLO - (Sistema de Informação do Câncer do Colo do útero), ainda cabe ao enfermeiro uma busca ativa das mulheres para a entrega de exames, pois $40 \%$ das mulheres não buscam seus resultados, e $94,8 \%$ desses exames não retirados contém alterações ginecológicas .

Segundo Tsuchiya CT, et al. (2017), as lesões encontradas no colo uterino consideradas precursoras possuem diferentes graus de evolução que podem ser classificados como neoplasia intraepitelial cervical (NIC). A NIC é um distúrbio que acomete o epitélio uterino e é classificado de acordo com sua proporção. NIC I é considerada de grau leve, esse distúrbio acontece somente nas camadas basais do epitélio. Já a NIC II é considerada de grau moderado avançando três a quatro camadas do epitélio, porém conserva as camadas superficiais. Na displasia grave NIC III todas as camadas do epitélio do colo uterino são acometidas. Se chegar a invadir o tecido conjuntivo tem-se o carcinoma escamoso invasivo (OLIVEIRA JRG, 2014).

Após a confirmação do diagnóstico de câncer de colo de útero a vida da mulher toma um caminho diferente do que ela idealizava, pois, essa doença traz mudança em todos os aspectos de sua vida, o tratamento provoca possíveis reações como mutilações, náuseas, vômitos, queda de cabelo e disfunções sexuais (MELO SCCS et al., 2009).

Conforme Corrêa LD (2011) o tratamento para o câncer de colo uterino dependerá do estadiamento da Federation of Gynecology and Obstretris (FIGO) e Tumor, Linfonodos e Metástase (TNM), com base no exame histológico, idade da mulher, condições clínicas apresentadas, levando em conta o desejo da mulher de reprodução.

Logo depois de diagnosticada com CCU, dá-se início ao tratamento, que muitas vezes é longo, causa reações de mal-estar e além de custos econômicos, traz preocupações com a recuperação e as pacientes acreditam na cura mesmo em estados avançados, trazendo para a mulher traumas que vão além da doença, acarreta medo de não alcançar a cura, de perder um órgão que tem uma grande representação feminina, além de problemas emocionais e psicossociais (MELO SCCS et al., 2009).

Corrêa LD (2011), afirma que a mulher diagnosticada com câncer de colo do útero passa por situações de ansiedade, medo, distúrbio de autoimagem, passando por dor, exsudatos, odores, incontinências fisiológicas, debilitações e eminência de morte. Por isso a equipe de enfermagem deve contribuir para melhora de vida dos pacientes em tratamento, tendo como base a Organização Mundial de Saúde (OMS) que avalia a qualidade de vida em vários aspectos, tais como: físicos, psicológicos, sociais levando-se em consideração a percepção da paciente em relação ao meio que a cerca (SANTOS LM e LIMA AKB, 2016).

Outro efeito que provoca impacto em pacientes portador de câncer é o estado nutricional, geralmente associado a altos índices de morbimortalidade, infecções, aumento do período de internação, dificulta a 
resposta ao tratamento e eleva os custos hospitalar por isso é importante um acompanhamento e avaliação contínua a essas pacientes (DALLABRIDA FA et al., 2014). Segundo Veras JMMF e Nery IS (2011), quando a mulher recebe o diagnóstico de CCU é importante que o enfermeiro já oriente a paciente e sua família sobre o tratamento, conhecer a história de vida da paciente, saber ouvir seus sentimentos, dúvidas, ensiná-las a lidar com possíveis alterações, reforçando diálogos para amenizar isolamento e o medo possíveis reações do tratamento, os cuidados a ser seguidos, a importância de adesão e continuidade da terapêutica, reforçando a importância do apoio familiar.

Outro aspecto relevante aos profissionais de saúde é considerar e utilizar as crenças para prestar cuidado, usando-as como aliada ao bem-estar, pois a espiritualidade vai além da religião, é vista como um propósito de vida (SANTOS LM e LIMA AKB, 2016; SALIMENA et al., 2014).

Para assegurar uma qualidade na assistência para as mulheres portadoras de CCU, o enfermeiro deve fornecer uma assistência de enfermagem integralizada, organizada e sem fragmentações, para isso, o enfermeiro possui uma ferramenta de trabalho que faz o diferencial a Sistematização da Assistência de Enfermagem (SAE) que proporciona um método de trabalho individualizado ao paciente com diagnósticos de enfermagem baseado identificação dos problemas, dando embasamento para intervenções e avaliação do resultado esperado (VARGAS MAO et al., 2013).

\section{CONSIDERAÇÕES FINAIS}

As atribuições do enfermeiro são e extrema importância em todo processo de doença do câncer de colo uterino, a começar na prevenção e se estende até os cuidados durante o tratamento da doença. Para tal fato é fundamental que o enfermeiro compreenda os principais fatores de risco que influenciam nesse processo de desenvolvimento do $\mathrm{CCU}$, podendo atuar tanto na prevenção primária com a educação em saúde contínua, como na secundária com o rastreamento para um diagnóstico de lesões precursoras antes de se tornarem invasivas com o exame de citopatologia oncótica. Quanto ao tratamento o enfermeiro tem que priorizar a mulher e a família com um olhar holístico, atendo-os com humanização, apoiando-os emocionalmente, informando como será o processo de tratamento, que geralmente é longo e traz insegurança a mulher e família, atentando aos efeitos colaterais durante o tratamento, fornecendo uma qualidade na assistência para as mulheres, sem fragmentações.

\section{REFERÊNCIAS}

1. ALMEIDA AF, HOLMES ES, LACERDA CCC et al. Métodos de detecção de câncer de colo uterino entre profissionais da saúde. J Nurse UFPE, 2015; 9 (1): 62-8.

2. AMARAL MS, GONÇALVES AG, SILVEIRA LCG. Prevenção do câncer de colo de útero: a atuação do profissional enfermeiro nas unidades básicas de saúde. Rev Cient Fac Mais, 2017; 197-223.

3. BARBOSA S, PINHEIRO M, JÚNIOR PPS. Ações do enfermeiro na prevenção primária e secundária do câncer de colo do útero. CARPE DIEM: Revista Cultural e Científica do UNIFACEX, 2011; 9 (1).

4. BATISTA RCL. Papel da enfermagem na prevenção, diagnóstico e tratamento do câncer de colo uterino: uma revisão integrativa. Universidade de Brasília- Faculdade de Ceilândia, Distrito Federal, 2015.

5. BORBA PC, TEXEIRA JC, MARTINS CMR et al. O que falta na luta contra o câncer de colo uterino. Diagnóstico e Tratamento, 2010; 15 (4): 198-202. Disponível em: http://files.bvs.br/upload/S/1413-9979/2010/v15n4/a1750.pdf. Acesso em: 03/marçode2019.

6. CASARIN MR, PICCOLI JCE. Educação em saúde para prevenção do câncer de colo do útero em mulheres do município de Santo Ângelo/RS. Ciência \& saúde coletiva, 2011; 16: 3925-3932.

7. CORRÊA LD. Diagnósticos de Enfermagem mais Prevalentes na Internação de Pacientes com Câncer de Colo do Útero no Hospital de Câncer II. In: Diagnósticos de Enfermagem mais Prevalentes na Internação de Pacientes com Câncer de Colo do Útero no Hospital de Câncer II. Instituto Nacional José de Alencar Gomes-Coordenação de educação, Rio de Janeiro, 2011.

8. COSTA FKM, WEIGERT SP, BURCI L et al. Os desafios do Enfermeiro perante a prevenção do câncer de colo do útero. Revista de gestão e saúde, 2017; 17(01); 55-62. 
9. DALLABRIDA FA, LORO MM, ROSANELLI CLSP et al. Qualidade de vida de mulheres tratadas por câncer do colo de útero. Revista da Rede de Enfermagem do Nordeste,2014; 15(1): 116-122.

10. DUARTE SJH, MATOS KF, OLIVEIRA PJM et al. Fatores de Risco Para Câncer Cervical em Mulheres Assistidas Por Uma Equipe de Saúde da Família em Cuiabá, MT, Brasil. Ciencia Y Enfermeria XVII, 2011; 17(1):71-80.

11. FARIAS ACB de, BARBIERI AR. Seguimento do câncer de colo de útero: estudo da continuidade da assistência à paciente em uma região de saúde. Escola Anna Nery, 2016; 20 (4).

12. INSTITUTO NACIONAL DE CÂNCER-(INCA). Estimativas 2018: incidência de câncer no Brasil. Rio de Janeiro, 2018. 38 p. Disponível em: <http://www1.inca.gov.br/estimativa/2018/index.asp >. Acesso em: 02 de março 2019.

13. INSTITUTO NACIONAL DE CÂNCER-(INCA). Estimativa 2018. Incidência do Câncer no Brasil. Rio de Janeiro: INCA, 2017. Disponível em: http://www.inca.gov.br/estimativa/2018/estimativa-2018.pdf. Acesso em: 03 de março de 2019

14. MATTOS CTD, SILVA GSV, OLIVEIRA TS et al. Percepção da mulher frente ao diagnóstico e tratamento do câncer do colo do útero-Subsídios para o cuidado de enfermagem. Revista Pró-UniverSUS, 2014; 5 (1): 27-35.

15. MELO SCCS, PRATES L, CARVALHO MDB et al. Alterações citopatológicas e fatores de risco para ocorrência do câncer de colo uterino. Revista gaúcha de enfermagem, 2009; 30 (4): 602.

16. MISTURA C, MISTURA C, SILVA RCC et al. Papel do enfermeiro na prevenção do câncer de colo uterino na estratégia saúde da família. Revista Contexto \& Saúde, 2011; 11 (20); 1161-1164.

17. NASCIMENTO RP do. A relação enfermeiro-cliente na consulta preventiva do câncer cérvico-uterino. Universidade Federal de Minas Gerais, Minas Gerais, 2010.

18. OLIVEIRA JRG de. Fatores que influenciam no câncer de colo do útero. Faculdade de Educação e Meio Ambiente, Roraima, 2014.

19. PAULA CG, RIBEIRO LB, PEREIRA MC et al. Atuação do enfermeiro da atenção básica frente ao controle do câncer uterino: revisão de literatura. Pós Rev. Centro Universitário Newton Paiva, 2013; 1 (5): 213-217.

20. SALIMENA AMO, OLIVEIRA MTL, PAIVA ACPC de et al. Mulheres portadoras de câncer de útero: percepção da assistência de enfermagem. Revista de Enfermagem do Centro Oeste Mineiro, 2014; 1 (4): 909-920.

21. SANTOS LM, DA SILVA LIMA, AKB. Câncer de colo do útero: papel do enfermeiro na prevenção e detecção precoce dessa neoplasia na atenção básica. 2019; 16 (3): 463-475. Disponível em: http://temasemsaude.com/wpcontent/uploads/2016/09/16328.pdf. Acesso em: 05 de fev. 2019

22. SANTOS UM, SOUZA SEBD. Papanicolau: diagnóstico precoce ou prevenção do câncer cervical uterino. Revista Baiana de Saúde Pública, v. 37, n. 4, p. 941, 2014.

23. TSUCHIYA CT, LAWRENCE T, KLEN MS et al. O câncer de colo do útero no Brasil: uma retrospectiva sobre as políticas públicas voltadas à saúde da mulher. JBES: Brazilian Journal of Health Economics/Jornal Brasileiro de Economia da Saúde, 2017; 9 (1): 137-147.

24. VARGAS MADO, ALMEIDA AMD, RADUNZ AM de et al. Módulo VIII: Linhas de cuidado: oncologia (câncer de mama, câncer de colo de útero e tumores de próstata). Florianópolis: UFSC; 2013; 123p.

25. VERAS JMMF, NERY IS. O significado do diagnóstico de câncer do colo uterino para a mulher. Revista Interdisciplinar NOVAFAPI, 2011; 4 (4): 13-18. 